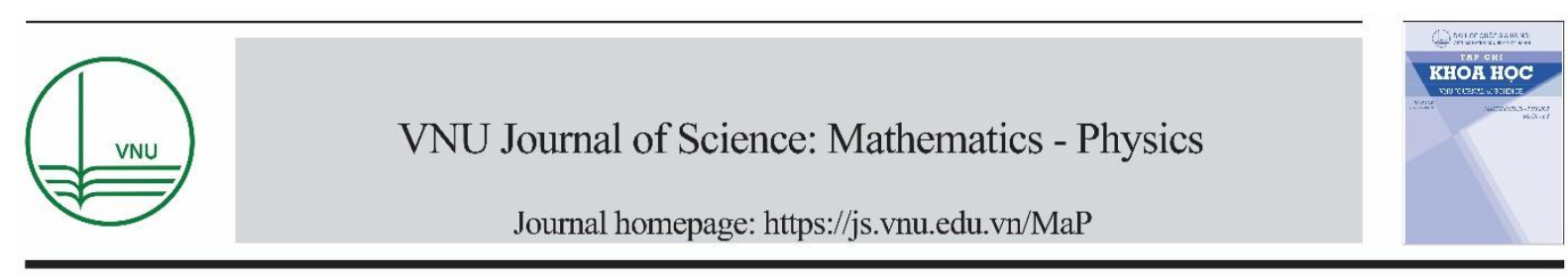

Original Article

\title{
Structure of $\mathrm{GeO}_{2}$ Glass under Compression Using Molecular Dynamics Simulation
}

\author{
Nguyen Mai Anh*, Nguyen Thi Thu Trang, \\ To Thi Nguyet, Nguyen Van Linh \\ Ha Noi University of Science and Technology, 1 Dai Co Viet, Hai Ba Trung, Hanoi, Vietnam \\ Received 14 December 2019 \\ Revised 11 June 2020; Accepted 15 August 2020
}

\begin{abstract}
We have investigated the behavior of $\mathrm{GeO} 2$ at the temperature of $300 \mathrm{~K}$ and the pressure from 0 to $100 \mathrm{GPa}$ by using the molecular dynamics simulation (the model with 5499 atoms). The results show that the $\mathrm{Ge}-\mathrm{Ge}, \mathrm{Ge}-\mathrm{O}$ bond distance increase but $\mathrm{O}-\mathrm{O}$ bond distance decreases when increasing the pressure. We find that the peak splitting of Ge-Ge at high pressure corresponds with the $\mathrm{Ge}-\mathrm{O}-\mathrm{Ge}$ and $\mathrm{O}-\mathrm{Ge}-\mathrm{O}$ bond angles. We also find that $\mathrm{O}-\mathrm{Ge}-\mathrm{O}$ bond angle decreases, and $\mathrm{Ge}-\mathrm{O}-$ Ge bond angle increases with pressure. The core-sharing-bond is major at ambient pressure, but fractions of edge and face-sharing-bonds increase with pressure.

Keywords: GeO2, High pressure, Microstructure, Radial distribution functions (RDFs), Molecular Dynamics simulation, clusters.
\end{abstract}

\section{Introduction}

Germanium dioxide $\left(\mathrm{GeO}_{2}\right)$ is a compound formed as a passivation layer on pure germanium in contact with atmospheric oxygen. In different temperatures and pressures, $\mathrm{GeO}_{2}$ exists in $\alpha$-quartz trigonal structure, rutile-like structure with tetragonal structure and an amorphous [1]. An amorphous form of $\mathrm{GeO}_{2}$ is similar to fused silica. The $\alpha$-quartz-type structure has been studied by using both experiment [2-4], simulation [5-7] and theory [8,9]. The calculations of the geometric structure and the physical properties of rutile-type $\mathrm{GeO} 2$ phase are also investigated in many studies [10]. The amorphous form of $\mathrm{GeO}_{2}$ is researched in $[2,11]$.

\footnotetext{
*Corresponding author.

Email address: anh.nm175671@sis.hust.edu.vn
}

https//doi.org/ 10.25073/2588-1124/vnumap.4445 
Because of its importance in industry, $\mathrm{GeO}_{2}$ glass has been extensively studied both experimentally and theoretically. In ref.[2], Dong et.al investigate the pressure-induced structural changes and polyamorphism of $\mathrm{GeO}_{2}$ glasses by using X-ray and Neutron diffraction. Extended X-Ray Absorption Fine Structure (EXAFS) experiment reveals that structural transformation in $\mathrm{GeO}_{2}$ glass occurs in a wide pressure range up to $54 \mathrm{GPa}$. At low pressure $(<5 \mathrm{GPa})$ the $\mathrm{Ge}-\mathrm{O}$ bond distance is almost unchanged with pressure. The degree of structural disorder increases with pressure. In 5-16 GPa pressure range, it shows the increase of Ge-O bond distance and bond disorder to maximum. In $16-23 \mathrm{GPa}$ pressure range, the Ge-O bond distance decreases significantly; increases slightly from 22,6 to $32,7 \mathrm{GPa}$; decreases as pressure increase from 32,4 to 41,4 GPa and slightly increases up to $54 \mathrm{GPa}$.

At ultra-high pressure, $\mathrm{GeO}_{2}$ glass has the polyamorphism with Coordination Number $(\mathrm{CN})$ more than 6. In the work [3], Kono et. al reveal that $\mathrm{CN}$ is6 between 22,6 to 37,9 GPa. At higher pressures, $\mathrm{CN}$ increases rapidly and reaches 7,4 at 91,7 $\mathrm{GPa}$.

The investigation shows that Radial Distribution Function (RDF) of Ge-Ge has double peak, so GeGe bond length comprises two value: 2.82 and $\AA$ at $22.6 \mathrm{GPa} ; 2,79$ and $3.24 \AA$ at $37.9 \mathrm{GPa} ; 2.73$ and $3.15 \AA$ at $49.4 \mathrm{GPa} ; 2.73$ and $3.13 \AA$ at $61.4 \mathrm{GPa}$. The double peak tends to merge into a single peak as pressure increases (>72.5 Gpa). In ref.[5], the authors also study the first peak splitting of Ge-Ge pair RDF. They investigate short range order (SRO) and intermediate range order (IRO) of $\mathrm{GeO}_{2}$ at $3500 \mathrm{~K}$ using molecular dynamics (MD), in pressure from 0 to $100 \mathrm{GPa}$.

They found that $\mathrm{GeO}_{4}$ tetrahedra link to each other to form a tetrahedral network. As pressure increases, tetrahedral network transits to octahedral network $\left(\mathrm{GeO}_{6}\right)$ via $\mathrm{GeO}_{5}$ polyhedra. At a middle pressure, $\mathrm{GeO}_{2}$ exists in three forms $\mathrm{GeO}_{4}, \mathrm{GeO}_{5}, \mathrm{GeO}_{6}$. $\mathrm{GeO}_{5}$-cluster reaches the maximum at 15-20 GPa. The authors found that it exists as an immediate configuration in structural transition process. Investigation shows that at low pressure, $\mathrm{GeO}_{\mathrm{x}}(\mathrm{x}=4,5,6)$ link to each other by one common oxygen ( corner-sharing bond, see figure 11) and at high pressure, by a corner-sharing bond, edge-sharing bond (two common oxygenssee figure 11), and face-sharing bond (three common oxygens, see figure 11). At high pressure, the $\mathrm{GeO}_{5}, \mathrm{GeO}_{6}$ polyhedra are dominant and tend to link each other by edge-sharing and face-sharing bonds, which become edge-sharing and face-sharing clusters. In ref.[12], the structure of $\mathrm{GeO}_{2}$ glass is investigated at pressures up to $17.5(5) \mathrm{GPa}$ using insitu time-of-flight neutron diffraction with a Paris-Edinburgh press employing sintered diamond anvils. At low pressure (5 GPa), it exists mainly in $\mathrm{GeO}_{4}$ units. In 5 to $10 \mathrm{GPa} \mathrm{GeO}_{4}$ units are replaced predominantly by $\mathrm{GeO}_{5}$ ones. At pressure beyond $10 \mathrm{GPa}, \mathrm{GeO}_{6}$ units begin to form.

Shanavas et.al investigated $\mathrm{GeO}_{2}$ at the high-pressure and temperature using molecular dynamics simulations [6]. They found that $\mathrm{GeO}_{2}$ system has a stable phase at ambient conditions of rutile type, in which the Ge-O are octahedrally coordinated. The rutile phase transforms to the tetrahedrally coordinated $\alpha$-quartz phase as the temperature increases up to around $1280 \mathrm{~K}$. Heating $\alpha$-quartz, it transforms to $\beta$-quartz at above $1020 \mathrm{~K}$ and melts at $1378 \mathrm{~K}$ to form a network-structure liquid. At 9 $\mathrm{GPa}, \alpha-\mathrm{GeO}_{2}$ transforms to a monoclinic phase. Their simulations on vitreous $\mathrm{GeO}_{2}$ displays a smoth variation of mixed coordinated state of 4, 5, 6 coordination in pressure between 6 to $10 \mathrm{GPa}$, as being reported by Guthrie et.al. The research also showed that at high pressures, liquid $\mathrm{GeO}_{2}$ transitions to a six-coordinated amorphous solid-like phase. Shanavas et.al [6] shows that Ge-O-Ge peak at $135^{\circ}$ in the $\alpha$-phase (at $300 \mathrm{~K}$ ) and at $145^{\circ}$ in $\beta$-phase (at $1100 \mathrm{~K}$ ). The intertetrahedral Ge-O-Ge angle bond increases with temperature in $300-900 \mathrm{~K}$ temperature range. At higher temperature $(900-1000 \mathrm{~K})$ it increases strongly. However, it almost changes from $1000 \mathrm{~K}$ to $1500 \mathrm{~K}$, decreases suddenlly from 1500 $\mathrm{K}$ to around $1600 \mathrm{~K}$ and decrease to $1900 \mathrm{~K}$. When increasing the temperature, $\mathrm{O}-\mathrm{Ge}-\mathrm{O}$ angle does not change, but from 1500 to $1900 \mathrm{~K}$, it increases a little. At pressure from 0 to $20 \mathrm{GPa}, \mathrm{O}-\mathrm{Ge}-\mathrm{O}$ angle has 
a peak at $90^{\circ}$ and another small peak at $170^{\circ}$. At pressure from 0 to $20 \mathrm{GPa}$ at $300 \mathrm{~K}$ and $1650 \mathrm{~K}$, the interpolyhedral Ge-O-Ge angle has a small peak at $85^{\circ}$ ascribable to edge-shared tetrahedra. Increasing the pressure, another peak appears around $90^{\circ}$, due to edge-shared octahedra.

The study [7] using MD simulation (in the micro-canonical ensemble, with systems at densities ranged from 3.16 to $6.79 \mathrm{~g} / \mathrm{cm} 3$, using a pairwise potential) shows that at around 3-7 GPa the main structural changes in amorphous $\mathrm{GeO}_{2}$ occur, changing from a network composed basically of $\mathrm{GeO}_{4}$ tetrahedra to the one composed of $\mathrm{GeO}_{6}$ octahedra.

In the study of Mei and Shen et.al [4], $\mathrm{GeO}_{2}$ is investigated by using X-ray in pressure up to 15.7 $\mathrm{GPa}$, the results show monotonic increase of the average coordination number of oxygen atoms around Ge with pressure from 4.2 at 5.1 GPa to 5.5 at $15.7 \mathrm{GPa}$. This reveals the structural transsition of silica glass under compression. However, the detail about the structural transformation is still not clarified.

In this paper, we investigate the $\mathrm{GeO}_{2}$ model at different pressures, at $300 \mathrm{~K}$ to find the change of RDFs, CN, angles of bonds and the connect of angles, distances and kinds of sharing bonds. We explain the peak splitting of $\mathrm{Ge}-\mathrm{Ge}$ at high pressure, $\mathrm{O}-\mathrm{Ge}-\mathrm{O}$ bond angle decreases, and $\mathrm{Ge}-\mathrm{O}-\mathrm{Ge}$ bond angle increases with pressure.

\section{Calculation Method}

We construct the models of germania glass with the two-body potential developed by OeffnerElliott (OE). The detail parameters of the potential are given in ref. [13]. The OE potential has been used in many works for a long time and is known to reproduce the main structural and mechanical properties of $\mathrm{GeO}_{2}$, see refs. [2, 6, 14-18]. In particular under pressure, the OE potential is known to reproduce the model with structure properties in good agreement with experiment [1-3, 12]. The glass models considered here contain 5499 atoms in cubic periodic simulation cells. They were obtained from a melt equilibrated at $6000 \mathrm{~K}$. After that the model is cooled to $3500 \mathrm{~K}$ and compressed to different pressures in $0-100 \mathrm{GPa}$ range. Next, the models are cooled to $300 \mathrm{~K}$ at cooling rate of $2.5 \mathrm{~K} / \mathrm{ps}$. Next, the models at different pressures are relaxed for a long time ( $10^{6}$ time steps) to get equilibrated state. The structural properties are calculated by averaging over 1000 configurations during the last $5 \times 10^{4}$ time steps.

\section{Results and Discussion}

In the present paper, we analyze the results of molecular dynamic simulation for amorphous $\mathrm{GeO}_{2}$ in 0-100 GPa pressure range, at $300 \mathrm{~K}$. The structure of $\mathrm{GeO}_{2}$ glass under compression will be clarified.

Coordination units: Figure 1 shows the pressure dependence of concentration of $\mathrm{GeO}_{\mathrm{x}}(\mathrm{x}=4,5,6)$ and $\mathrm{OGe}_{\mathrm{x}}(\mathrm{x}=2,3,4)$. At $0 \mathrm{GPa}$, most of the Ge atoms have four-fold coordination $(93.24 \%)$. The concentration of $\mathrm{GeO}_{4}$ decreases monotonously with the increase of pressure. At $100 \mathrm{GPa}$, its concentration is about $0.17 \%$. At pressure of $0 \mathrm{GPa}$, the concentration of $\mathrm{GeO}_{5}$ is $5.9 \%$, then increases to maximum value (50.6\%), then decreases gradually to $23.8 \%$ at $100 \mathrm{GPa}$. With increasing the pressure, the fraction of $\mathrm{GeO}_{6}$ monotonously increases from $0.86 \%$ at $0 \mathrm{GPa}$ to $77.03 \%$ at $100 \mathrm{GPa}$. At high pressure $(\mathrm{p}>=60 \mathrm{GPa})$, most of the Ge atoms have five-fold and six-fold coordination.

The concentration of $\mathrm{OGe}_{\mathrm{x}}(\mathrm{x}=2,3,4)$ also depends on the pressure. At the pressure from 0 to 100 $\mathrm{GPa}$, the fraction of $\mathrm{OGe}_{4}$ is small, it monotonously increases from $0 \%$ at $0 \mathrm{GPa}$ to $9.66 \%$ at $100 \mathrm{GPa}$. The fraction of $\mathrm{OGe}_{3}$ increases with pressure from $8.82 \%$ at $0 \mathrm{GPa}$ to $69.48 \%$ at $100 \mathrm{GPa}$. The fraction of $\mathrm{OGe}_{2}$ monotonously decreases from $91.18 \%$ to $20.88 \%$ at pressure of $0-100 \mathrm{GPa}$. 


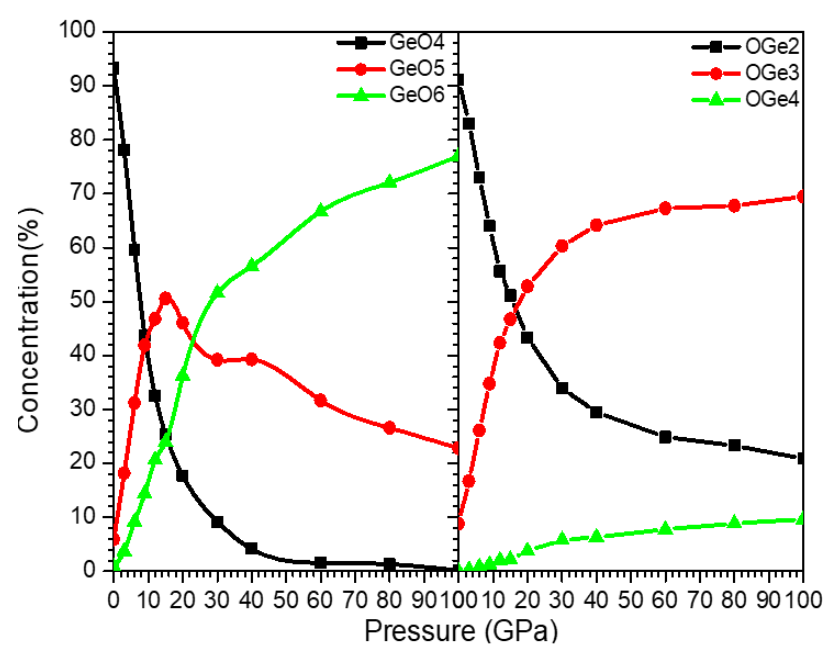

Figure 1. Concentration of $\mathrm{GeO}_{\mathrm{x}}(\mathrm{x}=4,5,6)$ and $\mathrm{Oge}_{\mathrm{x}}(\mathrm{x}=2,3,4)$ as a function.

Bond angle distribution (BAD): The $\mathrm{O}-\mathrm{Ge}-\mathrm{O}$ bond angle distribution (see Figure 2) in $\mathrm{GeO}_{4}$ (in 0$40 \mathrm{GPa}$ range) decreases from $105^{\circ}$ to $100^{\circ}$ with increasing pressure. The O-Ge-O bond angle distribution in $\mathrm{GeO}_{5}$ in $0-100 \mathrm{GPa}$ range has a main peak at around $85^{\circ}-90^{\circ}$ and a small peak at $165^{\circ}$ $170^{\circ}$. Investigation of $\mathrm{O}-\mathrm{Ge}-\mathrm{O}$ bond angle distribution in $\mathrm{GeO}_{6}$ at $3-100 \mathrm{GPa}$ shows the same results as $\mathrm{GeO}_{5}$.
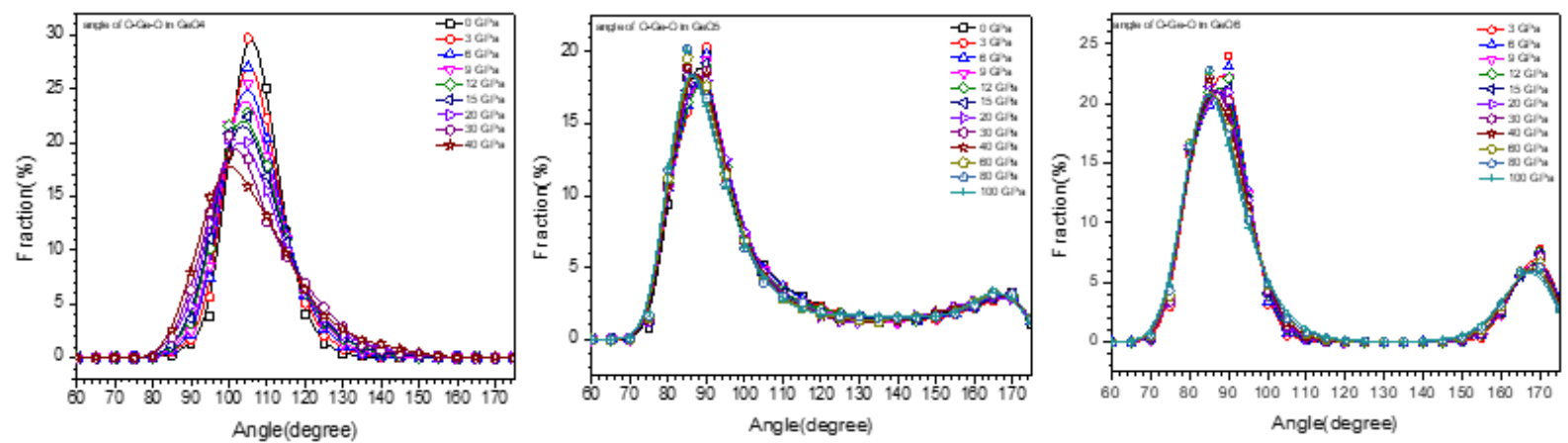

Figure 2. Fraction of angle of $\mathrm{O}-\mathrm{Ge}-\mathrm{O}$ in $\mathrm{GeO}_{\mathrm{x}}(\mathrm{x}=4,5,6)$.

The Ge-O-Ge bond angle distribution in $\mathrm{OGe}_{4}$ has one peak and two subpeaks in the left and right (see figure 3). The position of corresponding peaks are at $75^{\circ}, 90^{\circ}$ and around $125-130^{\circ}$. Investigating $\mathrm{OGe}_{3}$ in $0-100 \mathrm{GPa}$, we find that from 0 to $3 \mathrm{GPa}$, Ge-O-Ge BAD has two peaks are around $85^{\circ}-90^{\circ}$ and $115^{\circ}-120^{\circ}$ but from 6 to $100 \mathrm{GPa}$, the results show the same as $\mathrm{OGe}_{4}$ at pressure from 30 to $100 \mathrm{GPa}$. Investigating $\mathrm{OGe}_{2}$ in $0-100 \mathrm{GPa}$ range, we find that from 0 to $6 \mathrm{GPa}, \mathrm{Ge}-\mathrm{O}-\mathrm{Ge} \mathrm{BAD}$ has two peaks at around $85^{\circ}-90^{\circ}$ and $125^{\circ}-130^{\circ}$ but in $9-100 \mathrm{GPa}$ range, the Ge-O-Ge BAD of $\mathrm{OGe}_{2}$ has one peak and two smaller peaks in the left and right at around $75^{\circ}-80^{\circ}, 90^{\circ}-95^{\circ}$ and $125^{\circ}-130^{\circ}$.

Corner-, edge- and face-sharing bonds: Figure 4 shows that at low pressure ( $0 \mathrm{GPa})$, corner-sharingbonds are dominant (94.94\%), edge-sharing bond is $4.75 \%$ and face-sharing bond is $0.31 \%$. At $6 \mathrm{GPa}$, It exists corner- and edge-sharing bond. The concentration of corner-sharing-bonds is about $83.34 \%$, edge-sharing bonds are about $14.25 \%$ and face-sharing-bonds are about $2.41 \%$. In high pressure 
(100GPa), It exists three types: corner-sharing-bond with concentration of $68.82 \%$, edge-sharing-bond concentration of $24.69 \%$ and face-sharing-bond concentration of $6.49 \%$. We find that concentration of corner-sharing-bond decreases, fraction of face-sharing-bond increases.
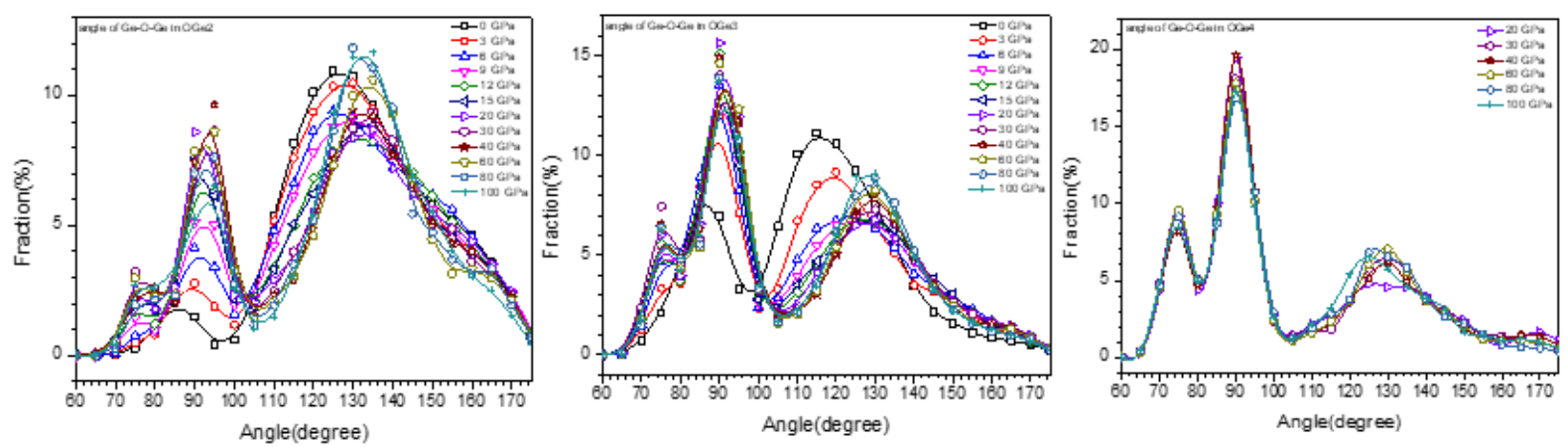

Figure 3. The Ge-O-Ge bond angle distribution in $\mathrm{GeO}_{\mathrm{x}}(\mathrm{x}=2,3,4)$.

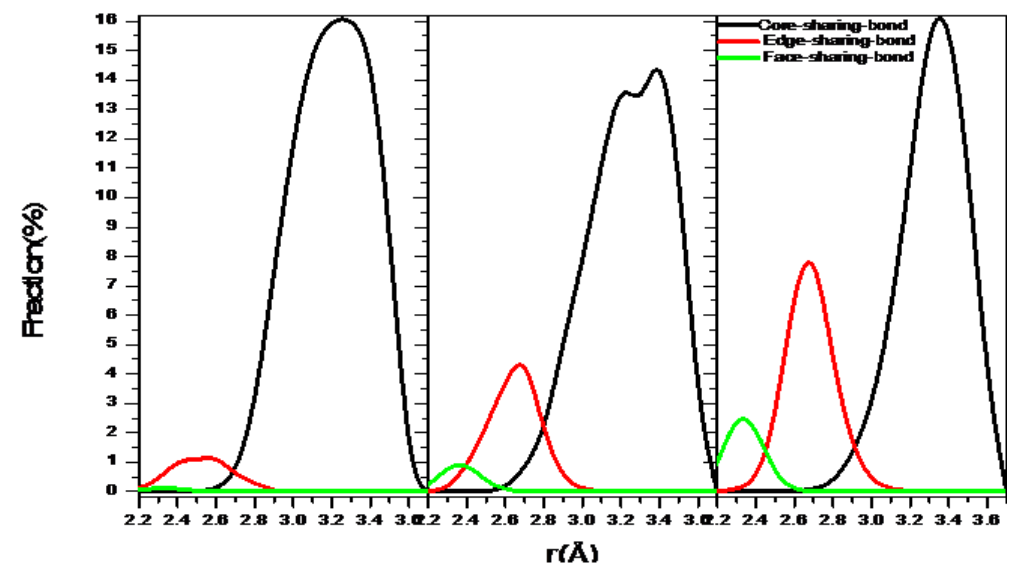

Figure 4. Fraction of core-, edge-, face-sharing bond in pressure range.

The size distribution of clusters: Table 1 shows that size of clusters decreases with increasing pressure, $\mathrm{GeO}_{4}$ units link to each other into the largest cluster at ambient pressure. At higher pressure, size of clusters is smaller, it means that the number of $\mathrm{GeO}_{4}$ decreases with pressure and they split into many smaller cluster. We also find that at high pressure (>40 GPa), the number of $\mathrm{GeO}_{4}$ clusters and the number of atoms in each cluster decrease. At $100 \mathrm{GPa}$, it has one cluster with 5 atoms.

Table 1. The cluster of $\mathrm{GeO}_{4}$ ( $\mathrm{Na}$ is the number of atoms of the clusters, $\mathrm{Nc}$ is the number of clusters having $\mathrm{Na}$ correspondly).

\begin{tabular}{|l|l|l|l|l|l|l|l|l|l|l|l|l|l|l|l|l|l|}
\hline \multicolumn{2}{|l|}{$0 \mathrm{GPa}$} & \multicolumn{2}{l|}{$6 \mathrm{GPa}$} & \multicolumn{2}{l|}{$12 \mathrm{GPa}$} & \multicolumn{2}{l|}{$20 \mathrm{GPa}$} & \multicolumn{2}{l|}{$40 \mathrm{GPa}$} & \multicolumn{2}{l|}{$60 \mathrm{GPa}$} & \multicolumn{2}{|l|}{$80 \mathrm{GPa}$} & \multicolumn{2}{l|}{$100 \mathrm{GPa}$} \\
\hline $\mathrm{Nc}$ & $\mathrm{Na}$ & $\mathrm{Nc}$ & $\mathrm{Na}$ & $\mathrm{Nc}$ & $\mathrm{Na}$ & $\mathrm{Nc}$ & $\mathrm{Na}$ & $\mathrm{Nc}$ & $\mathrm{Na}$ & $\mathrm{Nc}$ & $\mathrm{Na}$ & $\mathrm{Nc}$ & $\mathrm{Na}$ & $\mathrm{Nc}$ & $\mathrm{Na}$ \\
\hline 2 & 5 & 24 & 5 & 145 & $5-20$ & 186 & $5-20$ & 48 & 5 & 22 & 5 & 14 & 5 & 1 & 5 \\
\hline 1 & 5304 & 5 & 9 & 8 & $21-40$ & 6 & $21-40$ & 4 & 9 & & & 2 & 9 & & \\
\hline & & 1 & 3857 & 2 & $41-80$ & 1 & $40-45$ & 1 & 13 & & & & & & \\
\hline & & & & 1 & $80-160$ & & & 1 & 17 & & & & & & \\
\hline & & & & 3 & $160-430$ & & & & & & & & & & \\
\hline
\end{tabular}


Table 2 shows that in 12-40 GPa range, the $\mathrm{GeO}_{5}$ units forms clusters with size of 2000 to over 3000 atoms. At low pressure (0GPa), the number of clusters as well as their size are small. The size of $\mathrm{GeO}_{5}$ clusters increases and gets maximum at $20 \mathrm{GPa}$, then decreases with pressure.

Table 2. The clusters of GeO5 ( $\mathrm{Na}$ is the number of atoms of the clusters, $\mathrm{Nc}$ is the number of clusters having $\mathrm{Na}$ correspondly)

\begin{tabular}{|c|c|c|c|c|c|c|c|c|c|c|c|c|c|c|c|}
\hline \multicolumn{2}{|c|}{$0 \mathrm{GPa}$} & \multicolumn{2}{|c|}{$6 \mathrm{GPa}$} & \multicolumn{2}{|c|}{$12 \mathrm{GPa}$} & \multicolumn{2}{|c|}{ 20GPa } & \multicolumn{2}{|c|}{ 40GPa } & \multicolumn{2}{|c|}{$60 \mathrm{GPa}$} & \multicolumn{2}{|c|}{ 80GPa } & \multicolumn{2}{|c|}{$100 \mathrm{GPa}$} \\
\hline $\mathrm{Nc}$ & $\mathrm{Na}$ & $\mathrm{Nc}$ & $\mathrm{Na}$ & $\mathrm{Nc}$ & $\mathrm{Na}$ & $\mathrm{Nc}$ & $\mathrm{Na}$ & $\mathrm{Nc}$ & $\mathrm{Na}$ & $\mathrm{Nc}$ & $\mathrm{Na}$ & $\mathrm{Nc}$ & $\mathrm{Na}$ & $\mathrm{Nc}$ & $\mathrm{Na}$ \\
\hline 47 & $6-10$ & 58 & $6-20$ & 25 & $6-10$ & 17 & 6 & 43 & $6-20$ & 67 & $6-20$ & 94 & $\begin{array}{l}6- \\
20\end{array}$ & 122 & $\begin{array}{l}6- \\
20\end{array}$ \\
\hline 5 & $11-15$ & 5 & $21-40$ & 1 & $11-15$ & 1 & 11 & 4 & $21-40$ & 6 & $21-40$ & 13 & $\begin{array}{l}21- \\
40\end{array}$ & 10 & $\begin{array}{l}21- \\
40\end{array}$ \\
\hline 3 & $16-20$ & 3 & $41-60$ & 1 & $16-20$ & 1 & 16 & 1 & 54 & 6 & $41-60$ & 7 & $\begin{array}{l}41- \\
60\end{array}$ & 1 & $\begin{array}{l}41- \\
60\end{array}$ \\
\hline 3 & $21-25$ & 4 & $61-80$ & 1 & $21-25$ & 1 & 33 & 1 & 86 & 2 & $61-80$ & 6 & $\begin{array}{l}61- \\
80\end{array}$ & 1 & 78 \\
\hline 1 & $26-30$ & 2 & $81-100$ & 1 & 3348 & 1 & 3379 & 1 & 2432 & 1 & $\begin{array}{l}81- \\
100 \\
\end{array}$ & & & 1 & 156 \\
\hline & & 4 & $101-200$ & & & & & & & 5 & $\begin{array}{l}101- \\
200\end{array}$ & & & 1 & 173 \\
\hline & & 2 & $201-400$ & & & & & & & 1 & 540 & & & & \\
\hline
\end{tabular}

Table 3 shows that $\mathrm{GeO}_{6}$ forms clusters: At $0 \mathrm{GPa}$, the number and the size of the clusters are minimun. There are only 12 clusters, each of clusters has 7 to 14 atoms. Increasing pressure from 0 to 9 $\mathrm{GPa}$, the number of clusters also the size of them increase. At $9 \mathrm{GPa}$, there are 119 clusters and the biggest cluster has 161 atoms. Then, increase the pressure, we find that the size of clusters increase and the number of clusters decreases. At $12 \mathrm{GPa}$, there are 106 clusters, the biggest cluster has 177 atoms. At pressure $>30 \mathrm{GPa}$, each cluster has more than 4000 atoms, it is maximum at $100 \mathrm{GPa}$ with 5113 atoms. We find that at pressure $>40 \mathrm{GPa}$, the atoms convergeinto one cluster. The simulation model has 5499 atoms so the fraction and the concentration of $\mathrm{GeO}_{6}$ are dominant.

Table 3. The clusters of GeO6 ( $\mathrm{Na}$ is the number of atoms of the clusters,

$\mathrm{Nc}$ is the number of clusters having Na correspondly)

\begin{tabular}{|l|l|l|l|l|l|l|l|l|l|l|l|l|l|l|l|l|l|}
\hline \multicolumn{2}{|l|}{$0 \mathrm{GPa}$} & \multicolumn{2}{l|}{$6 \mathrm{GPa}$} & \multicolumn{2}{l|}{$12 \mathrm{GPa}$} & \multicolumn{2}{l|}{$20 \mathrm{GPa}$} & \multicolumn{2}{l|}{$40 \mathrm{GPa}$} & \multicolumn{2}{l|}{$60 \mathrm{GPa}$} & \multicolumn{2}{|l|}{$80 \mathrm{GPa}$} & \multicolumn{2}{l|}{$100 \mathrm{GPa}$} \\
\hline $\mathrm{Nc}$ & $\mathrm{Na}$ & $\mathrm{Nc}$ & $\mathrm{Na}$ & $\mathrm{Nc}$ & $\mathrm{Na}$ & $\mathrm{Nc}$ & $\mathrm{Na}$ & $\mathrm{Nc}$ & $\mathrm{Na}$ & $\mathrm{Nc}$ & $\mathrm{Na}$ & $\mathrm{Nc}$ & $\mathrm{Na}$ & $\mathrm{Nc}$ & $\mathrm{Na}$ \\
\hline 9 & 7 & 94 & $7-20$ & 78 & $7-20$ & 12 & 7 & 1 & 4456 & 1 & 4851 & 1 & 4995 & 1 & 5113 \\
\hline 2 & 11 & 4 & $21-40$ & 16 & $21-40$ & 1 & 11 & & & & & & & & \\
\hline 1 & 14 & 1 & 42 & 6 & $41-60$ & 2 & 13 & & & & & & & & \\
\hline & & 1 & 45 & 3 & $61-100$ & 1 & 16 & & & & & & & & \\
\hline & & & & 2 & $101-200$ & 2 & 18 & & & & & & & & \\
\hline & & & & & & 1 & 20 & & & & & & & & \\
\hline & & & & & & 1 & 41 & & & & & & & & \\
\hline & & & & & & 1 & 3150 & & & & & & & & \\
\hline
\end{tabular}


Radial distribution function (RDF): We find that the Ge-Ge RDF has many peaks at high pressure. From 0 to $3 \mathrm{GPa}$, the RDFs of Ge-Ge have one peak. The first peak of RDF shows that Ge-Ge bond length is $3.16 \AA$ at $0 \mathrm{GPa}$. From 6 to $9 \mathrm{GPa}$, the RDFs of Ge-Ge have one main peak and a small peak on the left. At $6 \mathrm{GPa}, \mathrm{Ge}-\mathrm{Ge}$ bond length comprises two values of $2.7 \AA$ and $3.2 \AA$. From 12 to 100 $\mathrm{GPa}$, the RDFs of Ge-Ge have three peaks. At $100 \mathrm{GPa}$, it consists of three peaks showing that $\mathrm{Ge}-\mathrm{Ge}$ bond lengths are $2.28,2.64$ or $3.32 \AA$. The first peaks of RDFs of Ge-O show Ge-O bond length is about $1.74-1.78 \AA$. The first peak positions shifts to the right with increasing pressure. The RDFs of O-O show that O-O bond length is about from 2.5 to $2.8 \AA$. The first peak shift to the left as pressure increases. At pressure beyond $9 \mathrm{GPa}$, the O-O RDF has a small peak at around $3.6 \AA$ after the first peak.
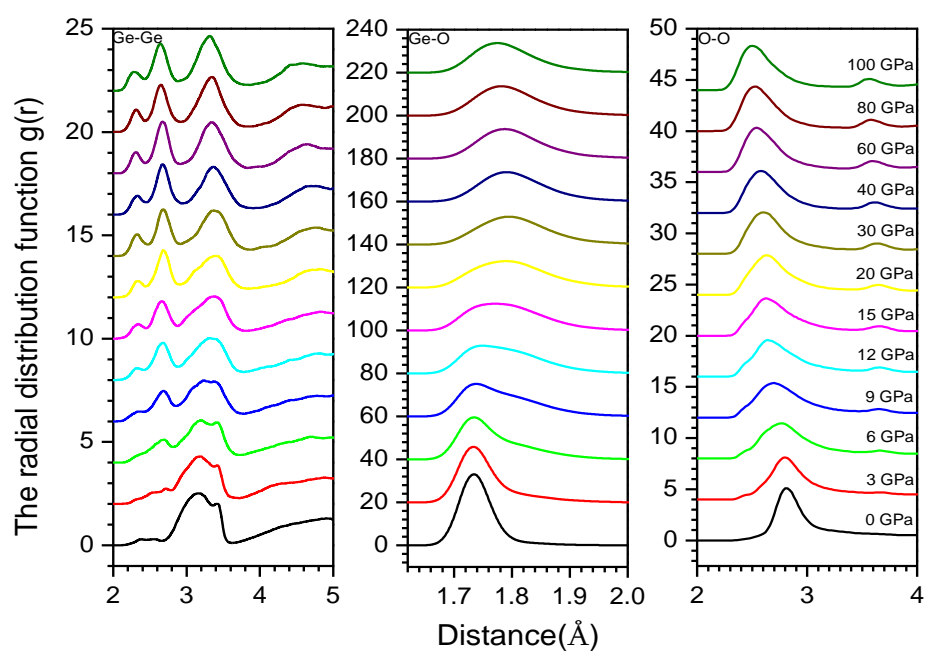

Figure 5. Radial distribution functions of $\mathrm{Mg}-\mathrm{Mg}, \mathrm{Mg}-\mathrm{O}$, and $\mathrm{O}-\mathrm{O}$ pairs at different pressures.

The peaks splitting of Ge-Ge RDF: The Ge-Ge distance depends on the bond type. At high pressure, we find that it has three peaks corresponding to corner-, edge- and face-sharing bonds (see figure 5). The distances of Ge-Ge are different with each sharing bond. The Ge-Ge distance depends on bond type. So, the Ge-Ge RDF has three peaks at high pressure. At low pressure (0GPa), it exists mainly cornersharing bonds and has one peak.

The distance of Ge-Ge also depends on the Ge-O-Ge bond angle.

$$
d_{G e-G e}=\sqrt{d_{O-G e}^{2}+d_{O-G e}^{2}+2 * d_{O-G e} d_{O-G e} \cos G e-\bar{O}-G e}
$$

Figure 6 shows that at high pressure (100 GPa), The Ge-O-Ge BAD has three peaks at $75^{\circ}, 90^{\circ}$ and $130^{\circ}$. So, the Ge-Ge RDF has three peaks corresponding with Ge-Ge bond lengths of 2.28, 2.64 and 3.32 $\AA$ A At low pressure (0GPa), It has two peaks (one main peak and a small peak on the left), we find that the RDF has one peaks and a shoulder. We also find that the peaks of Ge-Ge RDF shift to the right with increasing the pressure. Because the distance of $\mathrm{Ge}-\mathrm{O}$ increases with pressure, the distance of $\mathrm{Ge}-\mathrm{Ge}$ also increases.

Bond distance: Figure 7 shows that the peaks of $\mathrm{Ge}-\mathrm{O}$ bond distance distribution in $\mathrm{GeO}_{\mathrm{x}}(\mathrm{x}=4,5$, 6) shifts to the left with increasing the pressure. At pressure in 0-40 GPa range, Ge-O bond length in $\mathrm{GeO}_{4}$ decreases from $1.74 \AA$ to $1.72 \AA$. At pressure from $3-100 \mathrm{GPa}, \mathrm{Ge}-\mathrm{O}$ bond length in $\mathrm{GeO}_{5}$ decreases from $1.78 \AA$ to $1.76 \AA$. At pressure from 3 to $100 \mathrm{GPa}$, the $\mathrm{Ge}-\mathrm{O}$ bond length in $\mathrm{GeO}_{6}$ decreases from $1.88 \AA$ to $1.78 \AA$. 


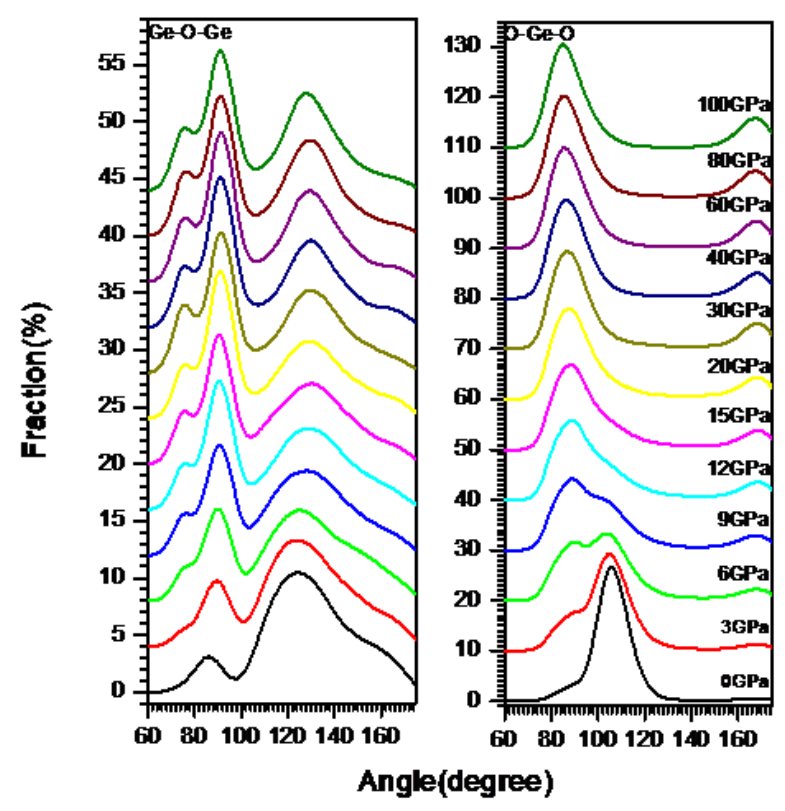

Figure 6. The Ge-O-Ge and O-Ge-O bond angle distribution at different pressures.

Figure 8 shows the distance Ge-O of $\mathrm{OGe}_{\mathrm{x}}(\mathrm{x}=2,3,4)$. Investigating $\mathrm{OGe}_{4}$ in $20-100 \mathrm{GPa}$, we find that the Ge-O length bond decreases from $1.84 \AA$ to $1.8 \AA$. At pressure of $0-100 \mathrm{GPa}$, the Ge-O length bond increases from $1.76 \AA$ (in $0 \mathrm{GPa}$ ) to maximum value at $1.8 \AA$ (in $60 \mathrm{GPa}$ ) then decreases to $1.78 \AA$ (in $100 \mathrm{GPa}$ ). The Ge-O bond length increases from $1.74 \AA$ (in $0 \mathrm{GPa}$ ) to maximum value at $1.78 \AA$ (in $30-40 \mathrm{GPa}$ range) then decrease to $1.78 \AA$ (in $100 \mathrm{GPa}$ ).

The distance of Ge-O increases with the pressure: The Ge-O distance increases from $1.74 \AA$ to 1.78 $\AA$ with pressure from 0 to $100 \mathrm{GPa}$. With increasing the pressure, the Ge-O CN increase, the result shows that coulomb repulsions between $\mathrm{Ge}$ and $\mathrm{Ge}$, between $\mathrm{O}$ and $\mathrm{O}$ increase, leading to increasing $\mathrm{Ge}-\mathrm{O}$ bond length. The $\mathrm{Ge}-\mathrm{O}$ distances in $\mathrm{GeO}_{\mathrm{x}}(\mathrm{x}=4,5,6)$ decreases with increasing pressure but the Ge-O distances in $\mathrm{GeO}_{6}>$ the ones in $\mathrm{GeO}_{5}>$ the ones $\mathrm{GeO}_{4}$ (see Figure 8). The fraction of $\mathrm{GeO}_{6}$ increases, the fraction of $\mathrm{GeO}_{4}$ and $\mathrm{GeO}_{5}$ decreases with increasing pressure so that the distances of $\mathrm{Ge}$ $\mathrm{O}$ increases. Both of the $\mathrm{Ge}-\mathrm{O}$ distances in $\mathrm{OGe}_{2}$ and $\mathrm{OGe}_{3}$ also increases with the pressure. The fraction of $\mathrm{OGe}_{2}$ and $\mathrm{OGe}_{3}$ increases with increasing pressure so the $\mathrm{Ge}-\mathrm{O}$ distance increases.
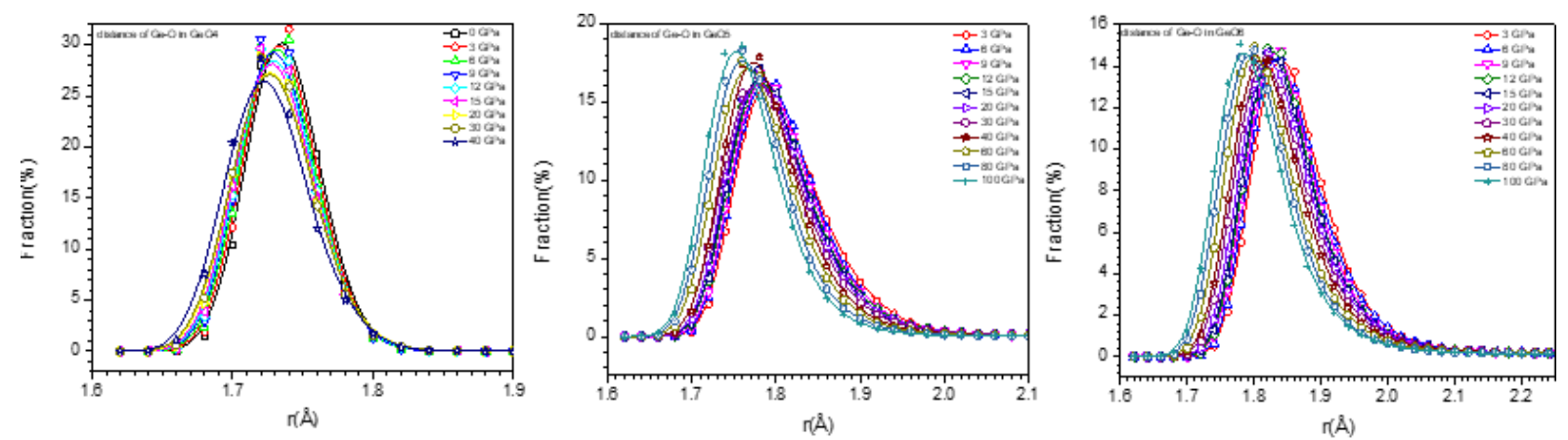

Figure 7. Fraction of distance of $\mathrm{Ge}-\mathrm{O}$ in $\mathrm{GeO}_{\mathrm{x}}(\mathrm{x}=4,5,6)$. 

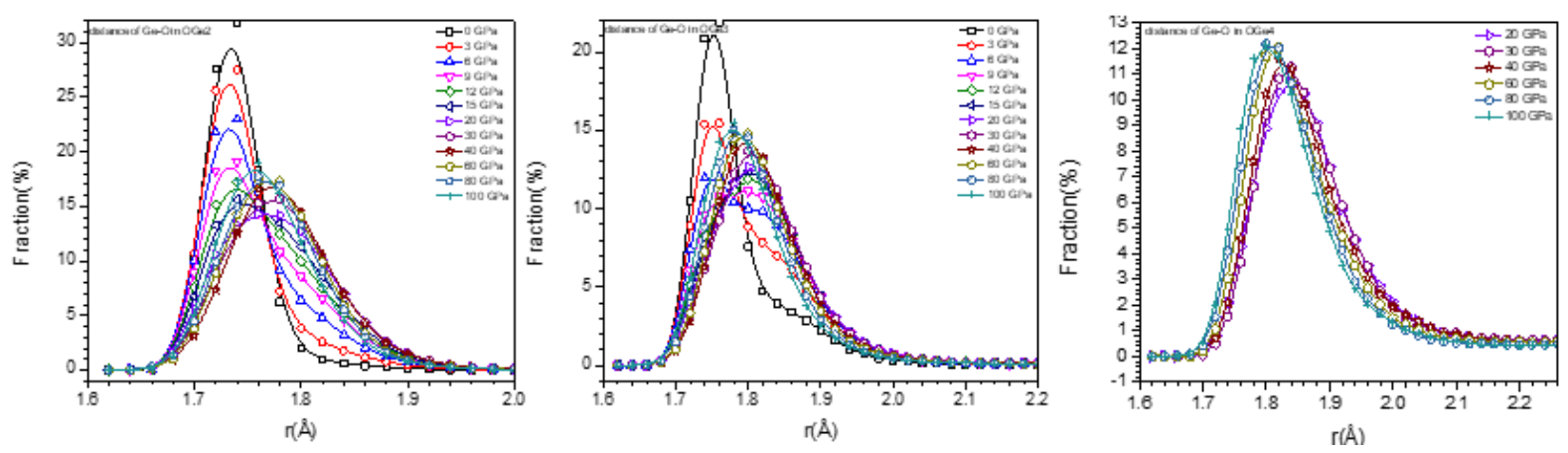

Figure 8. The Ge-O bond distance distribution in $\mathrm{GeO}_{\mathrm{x}}(\mathrm{x}=2,3,4)$.

The distance of $\mathrm{O}-\mathrm{O}$ decreases when increasing the pressure: With increasing the pressure, the $\mathrm{O}$ Ge-O bond angle decreases from $105^{\circ}$ to $85^{\circ}$ (see Figure 5) and the distance of O-O decreases from 2.8 to $2.5 \AA$. O-Ge-O BAD (Figure 5) has one more peak at $170-175^{\circ}$ at high pressure so that the RDF of $\mathrm{O}-\mathrm{O}$ has one peak at 3.6 $\mathrm{A}$. This distance is approximately double the distance of Ge-O.

$$
d_{O-O}=\sqrt{d_{O-G e}^{2}+d_{O-G e}^{2}+2 * d_{O-G e} d_{O-G e} \cos O-\overline{G e}-O}
$$

\section{Conclusion}

The paper reported the microstructure of $\mathrm{GeO}_{2}$ glass by using the molecular dynamic method. It showed that: $\mathrm{i} / \mathrm{The}$ fraction of $\mathrm{GeO}_{\mathrm{x}}(\mathrm{x}=4,5,6)$ and $\mathrm{OGe}_{\mathrm{x}}(\mathrm{x}=2,3,4)$ changes significantly in considered pressure range; ii/ The $\mathrm{O}-\mathrm{Ge}-\mathrm{O}$ bond angle decreases with increasing pressure. The change of $\mathrm{Ge}-\mathrm{O}-\mathrm{Ge}$ $\mathrm{BAD}$ under compression resulting in the change of $\mathrm{Ge}-\mathrm{Ge}$ and $\mathrm{O}-\mathrm{O}$ distance and formation of edge-, face-sharing-bonds. The fractions of edge-, face-sharing-bonds is increase with pressure and this is the cause of the first peak splitting of Ge-Ge RDF at high pressure; iii/ The glassy network structure of $\mathrm{GeO}_{2}$ changes significantly under compression, the $\mathrm{GeO}_{4}$ units tend to link each other forming $\mathrm{GeO}_{4}$ clutsers. Similar $\mathrm{GeO}_{5}$ and $\mathrm{GeO}_{6}$ also tend to form $\mathrm{GeO}_{5}$ and $\mathrm{GeO}_{6}$ clusters. This shows the polyamorphism in $\mathrm{GeO}_{2}$ glass at high pressure. The $\mathrm{O}-\mathrm{O}$ distances decreases, meanwhile $\mathrm{Ge}-\mathrm{O}$ distance increases with pressure.

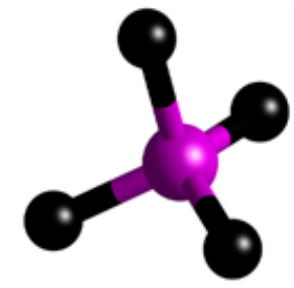

$\mathrm{A} \mathrm{GeO}_{4}$ atoms

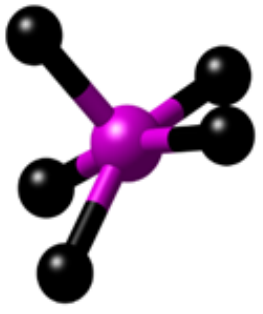

$\mathrm{A} \mathrm{GeO}$ atoms

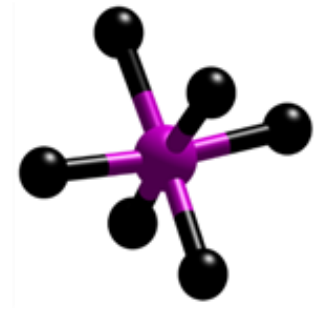

$\mathrm{A} \mathrm{GeO}_{6}$ atoms

Figure 9. The structure of $\mathrm{GeO}_{\mathrm{x}}(\mathrm{x}=4,5,6)$. 


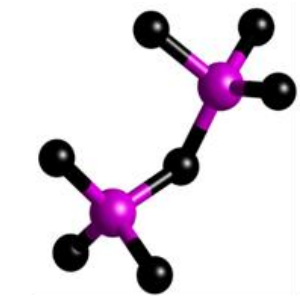

$\mathrm{A} \mathrm{GeO}_{4}$ cluster has 9 atoms

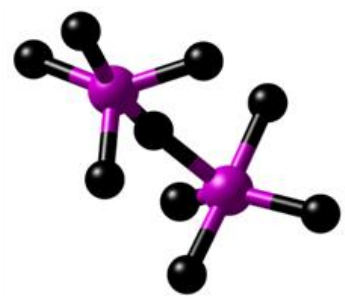

$\mathrm{A} \mathrm{GeO}_{5}$ cluster has 11 atoms

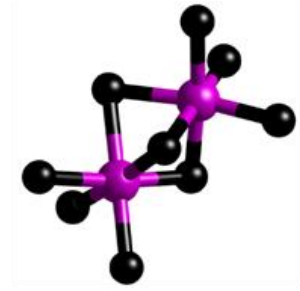

A GeO ${ }_{6}$ cluster has 11 atoms

Figure 10. Linkage between $\mathrm{GeO}_{x}(x=4,5,6)$ in clusters.

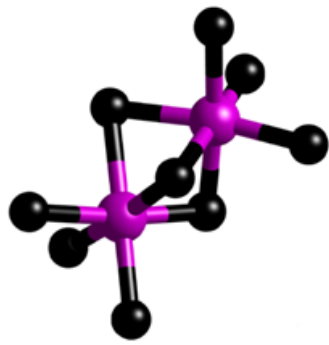

Face-sharing-bond

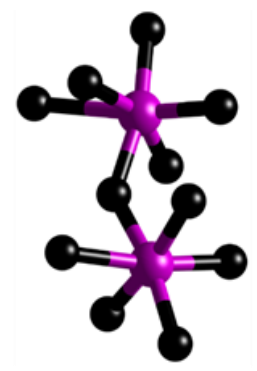

Core-sharing-bond

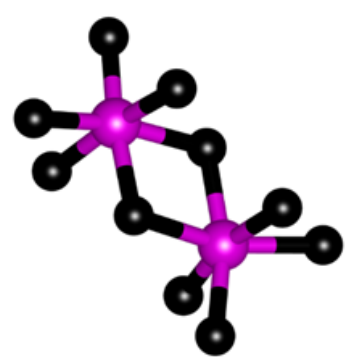

Edge-sharing-bond

Figure 11. The structure of core-, edge-, face-sharing bonds.

\section{References}

[1] M. Micoulaut, L. Cormier, G.S. Henderson, The structure of amorphous, crystalline and liquid GeO2, J. Phys.: Condens. Matter 18 (2006) R753-R784. http://doi.org/10.1088/0953-8984/18/45/R01.

[2] Dong et.al, Revisiting local structural changes in $\mathrm{GeO} 2$ glass at high pressure. Journal of Physics: Condensed Matte (2017) 29 465401, https://doi.org/10.1088/1361-648X/aa8d50.

[3] Yoshio Konoa,Curtis Kenney-Bensona, Daijo Ikutaa, Yuki Shibazakib, Yanbin Wangc, and Guoyin Shena, Ultrahigh-pressure polyamorphism in GeO2 glass with coordination number $>6$. PNAS (2016-03-29) vol 113, no.13, 3436-3441 www.pnas.org/lookup/suppl/doi:10. 1073/pnas.1524304113/-/DCSupplementa.

[4] Q. Mei, S. Sinogeikin, G. Shen, S. Amin, C. J. Benmore, and K. Ding, High-pressure x-ray diffraction measurements on vitreous $\mathrm{GeO} 2$ under hydrostatic conditions. Physical review. B 81, 174113 (2010), https://doi.org/10.1103/PhysRevB.81.174113.

[5] Tran Thuy Duong, Toshiaki Iitaka, Pham Khac Hung, Nguyen Van Hong, The first peak splitting of the Ge-Ge pair $\mathrm{RDF}$ in the correlation tonetwork structure of GeO2 under compression. Journal of Non-Crystalline Solids 459 (2017) 103-110, https://doi.org/10.1016/j.jnoncrysol.2017.01.003.

[6] Shanavas et.al, Classical molecular dynamics simulations behavior of $\mathrm{GeO} 2$ under high pressures and at high temperatures, Phys. Rev. B 73 (2006), 094120 https://doi.org/10.1103/PhysRevB.73.094120.

[7] Joaquín Peralta, Gonzalo Gutiérrez, Pressure-induced structural transition in amorphous GeO2: a molecular dynamics simulation. Eur. Phys. J. B 87, 257 (2014), https://doi.org/10.1140/epjb/e2014-50176-3.

[8] C. Sevik, C. Bulutay, J. Mater. Theoretical study of the insulating oxides and nitrides: $\mathrm{SiO} 2, \mathrm{GeO} 2, \mathrm{Al} 2 \mathrm{O} 3, \mathrm{Si} 3 \mathrm{~N} 4$, and Ge3N4, Sci. 42 (2007) 6555-6565, https://doi.org/10.1007/s10853-007-1526-9.

[9] Q.J. Liu, Z.T. Liu, L.P. Feng, H. Tian, First-principles study of structural, elastic, electronic and optical properties of rutile $\mathrm{GeO} 2$ and alpha-quartz GeO2 Solid State Sciences 12 (2010) 1748-1755, https://doi.org/10.1016/j.solidstatesciences.2010.07.025. 
[10] Z. Lodziana, K. Parlinski, J. Hafner, Ab-initio studies of high-pressure phase-transitions in GeO2, Phys. Rev. B 63 (2001) 134106, https://doi.org/10.1103/PhysRevB.63.134106.

[11] M Vaccari, G Aquilanti, S Pascarelli and O Mathon, A new EXAFS investigation of local structural changes in amorphous and crystalline $\mathrm{GeO} 2$ at high pressure. J. Phys.: Condens. Matter 21 (2009) 145403 (8pp), https://doi.org/10.1088/0953-8984/21/14/145403.

[12] Salmon et.al, Erratum: Density-driven structural transformations in network forming glasses: a high-pressure neutron diffraction study of $\mathrm{GeO} 2$ glass up to $17.5 \mathrm{GPa}$. IOPscience. Journal of Physics: Condensed Matte 24 (2012) 439601 (1pp), https://doi.org/10.1088/0953-8984/18/45/R01.

[13] R.D. Oeffner, S.R. Elliott, Interatomic potential for germanium dioxide empirically fitted to an ab-initio energy surface, Phys. Rev. B 58 (22) (1998) 14791-14803, https://doi.org/10.1103/PhysRevB.58.14791.

[14] J. Peralta, G. Guti errez, and J. Rogan. Structural and vibrational properties of amorphous GeO2: a molecular dynamics study. J. Phys.: Condens. Matter, 20(14):145215, 2008, https://doi.org/10.1088/0953-8984/20/14/145215

[15] P.K. Hung, L.T. Vinh, N.T. Nhan, N.V. Hong, and T.V. Mung. Local structure of liquids Al2O3 and GeO2 under densification. J. Non-Cryst. Solids, 354:3093-3097, 2008. https://doi.org/10.1016/j.jnoncrysol.2008.01.010.

[16] T. Li, S. Huang, and J. Zhu. The structure and void analysis of pressure-induced amorphous GeO2: Molecular dynamics simulation.Chem. Phys. Lett., 471 (4-6): 253-257, 2009. http://doi.org/ 10.1016/j.cplett.2009.02.059.

[17] M. Hawlitzky, J. Horbach, S. Ispas, M. Krack, and K. Binder. Comparative classical and ab initio molecular dynamics study of molten and glassy germanium dioxide. J. Phys.: Condens. Matter, 20 (28):285106, 2008, https://doi.org/10.1088/0953-8984/20/28/285106.

[18] D. Marrocchelli, M. Salanne, P.A. Madden, C. Simon, and P. Turq.The construction of a reliable potential for GeO2 from first principles. Mol. Phys., 107(4-6):443-452, 2009, https://doi.org/10.1080/00268970902845347. 